\title{
Interferon consensus sequence binding protein-induced cell proliferation is mediated by TGF- $\beta$ signaling and p38 MAPK activation
}

\author{
Jee Young Sung*, Heejung Kim*, Yong-Nyun Kim, Yoon Sook Na and Byung-Kiu Park
}

Interferon consensus sequence binding protein (ICSBP), also known as interferon regulatory factor (IRF)-8, is a member of the interferon (IFN)- $\gamma$ regulatory transcription factors. Studies have suggested a connection between TGF- $\beta$ signaling and IRFs. Thus, we investigated the effect of ICSBP on transforming growth factor (TGF)- $\beta$ signaling in HL-60, an acute promyelocytic leukemia cell line. Stable expression of ICSBP in HL-60 cells resulted in strong induction of TGF- $\beta$ receptor expression and activation of non-Smad as well as Smad pathways. ICSBP expression also augmented cell growth. ICSBP knockdown with small interfering RNA (siRNA) attenuated cell growth and decreased TGF- $\beta$ receptor I (TGF- $\beta$ RI) expression. In addition, reduction of TGF- $\beta$ RI using siRNA or pharmacological inhibitor reduced growth of ICSBP-expressing cells. ICSBP expression also led to increased phosphorylation and activation of Akt and p38 MAPK. However, p38 MAPK, but not PI3K-Akt, inhibition abrogated ICSBP-mediated proliferation. Furthermore, siRNA knockdown of either ICSBP or TGF- $\beta$ RI resulted in decreased p38 activation. Intriguingly, TGF- $\beta$-activated kinase 1 (TAK-1), which phosphorylates p38, was activated in ICSBP-expressing cells and its activity was reduced by TGF- $\beta$ RI inhibition. Finally, siRNA knockdown of ICSBP or TGF- $\beta$ RI reduced TAK-1 phosphorylation. This study identifies a novel role for ICSBP in regulating cell growth via TGF- $\beta$ receptor upregulation and subsequent activation of the TGF- $\beta$ receptor/TAK-1/p38 pathway.

Laboratory Investigation (2011) 91, 1304-1313; doi:10.1038/labinvest.2011.90; published online 30 May 2011

KEYWORDS: cell proliferation; ICSBP; p38; TAK-1; TGF- $\beta$ R

The transforming growth factor (TGF) $-\beta$ family is comprised of numerous factors, including TGF- $\beta$, bone morphogenetic proteins, activin, inhibin, and nodal. ${ }^{1}$ TGF- $\beta$ regulates many cellular functions, such as cell growth, migration, differentiation, and apoptosis. ${ }^{2}$ Although this cytokine exerts tumor suppressive activity, it also promotes tumorigenesis on deregulation of TGF- $\beta$ signaling. For example, during the early stages of cancer, TGF- $\beta$ inhibits epithelial cell growth. ${ }^{3}$ However, in later stages, TGF- $\beta$ potentiates tumor progression by reprogramming epithelial cells to become mesenchymal cells (also known as the epithelial-to-mesenchymal transition (EMT)), which is important for tumor metastasis and invasion. ${ }^{4}$ Moreover, TGF- $\beta 1$ overexpression has been associated with breast, lung, pancreatic, gastric, and liver cancer. ${ }^{5}$ High level of TGF- $\beta$ in infiltrating breast carcinoma has been associated with metastasis, indicating a link between TGF- $\beta$ levels and metastatic disease. ${ }^{2}$
TGF- $\beta$ binds to the TGF- $\beta$ receptor II (TGF- $\beta$ RII), resulting in the recruitment of TGF- $\beta$ receptor I (TGF- $\beta$ RI) and formation of active signaling complexes. TGF- $\beta$ RII, a constitutively active Ser/Thr kinase, activates TGF- $\beta$ RI via phosphorylation, resulting in subsequent activation of the receptor-regulated Smads, such as Smad2 and Smad3, by phosphorylation. Once activated, Smad2 and Smad3 form a complex with Smad4, and these complexes translocate into the nucleus to regulate gene expression. ${ }^{1,6-8}$ Inhibitory Smads (eg, Smad6 and Smad7) antagonize TGF- $\beta$ signaling by blocking receptor-regulated Smad activation or mediating TGF- $\beta$ R degradation. In addition to Smad-dependent pathways, non-canonical TGF- $\beta$ signaling pathways have been proposed. For example, TGF- $\beta$ R can interact with interleukin-1 receptor/TRAF6/TAK1 and activate JNK and p38. ${ }^{9}$ TGF- $\beta$ can also stimulate the ERK/MAPK pathway by activating Ras, which is important for EMT. ${ }^{10}$ Finally, TGF- $\beta$ has

Pediatric Oncology Branch, National Cancer Center, Gyeonggi-do, Korea

Correspondence: Dr B-K Park, MD, PhD, Pediatric Oncology Branch, National Cancer Center, 323 Ilsan-ro, Ilsandong-gu, Goyang-si, Gyeonggi-do 410-769, Korea. E-mail: bkpark@ncc.re.kr

${ }^{*}$ These authors contributed equally to this work.

Received 17 November 2010; revised 18 April 2011; accepted 18 April 2011 
been shown to activate PI3K-Akt signaling, which is required for TGF- $\beta$-mediated EMT and cell migration, ${ }^{11}$ as well as fibroblast proliferation. ${ }^{12}$

Interferon consensus sequence-binding protein (ICSBP), also known as interferon regulatory factor (IRF)-8, is a transcription factor induced by interferon (IFN) $-\gamma$ in the immune system. ${ }^{13}$ ICSBP has an essential role in macrophage maturation and B-cell development. ${ }^{14,15}$ Similar to other members of the IRF family, ICSBP binds to the IFN-stimulated response element and activates or represses target genes ${ }^{16}$ to regulate myeloid cell differentiation. ICSBP ${ }^{-1-}$ mice have been reported to develop chronic myelogenous leukemia (CML)-like syndrome and are more susceptible to viral infection. ${ }^{17}$ Consistent with this notion, ICSBP transcripts are lacking in many patients with CML and acute myelogenous leukemia (AML). ${ }^{18}$ In addition, ectopic expression of ICSBP can inhibit the mitogenic activity of $\mathrm{Bcr}-\mathrm{Abl}$ and ameliorate Bcr-Abl-mediated murine myeloid leukemia in vivo, ${ }^{14}$ indicating that ICSBP behaves as a tumor suppressor in certain hematopoietic malignancies. Furthermore, a recent study demonstrated that ICSBP expression is downregulated in non-hematopoietic tumors, such as nasopharyngeal, esophageal, and other carcinomas. ${ }^{19}$

Several lines of evidence suggest a connection between TGF- $\beta$ signaling and IRFs. An IRF-Smad sequence alignment revealed that IRFs, including ICSBP, contain a conserved transactivation domain also shared by Smad $4 .{ }^{20}$ Upregulation of ICSBP by TGF- $\beta$ during dendritic cell development is well established. ${ }^{21}$ In addition, TGF- $\beta$ can induce IRF-1, which mediates growth inhibition by TGF- $\beta$ in human hepatocarcinoma cells. ${ }^{22}$ Furthermore, IRF-7 can interact with Smad3, and TGF- $\beta /$ Smad 3 signaling regulates many IRF-7 functions, including induction of IFN $-\alpha$ and $-\beta .^{23}$ Given that IRFs, including ICSBP, are induced and/or involved in TGF- $\beta$ signaling and ICSBP is a known tumor suppressor, it is possible that this protein is associated with the growth inhibitory effect of TGF- $\beta$ or vice versa. To test this hypothesis, ICSBP was overexpressed in the human myeloid leukemia cell line HL-60, which lacks detectable levels of ICSBP. Our data demonstrate that this overexpression resulted in enhanced TGF- $\beta$ signaling, leading to increased cell proliferation. We also show that the TAK-p38 pathway is critical for ICSBP/ TGF- $\beta$-mediated cell growth, revealing a novel function for ICSBP in TGF- $\beta$-regulated cell proliferation. Therefore, despite the well-established tumor suppressor nature of ICSBP, these novel findings link the ICSBP expression to cell growth promotion.

\section{MATERIALS AND METHODS}

\section{Cell Culture, Antibodies, and Reagents}

The HL-60 human acute promyelocytic leukemia cell line, U937 human monocytic cell line were obtained from American Type Culture Collection (Rockville, MD) and maintained in RPMI 1640 medium (Gibco Life Technologies, Carlsbad, CA) containing $50 \mathrm{U} / \mathrm{ml}$ penicillin, $50 \mathrm{mg} / \mathrm{ml}$ streptomycin, $2 \mathrm{mM}$ L-glutamine, and $10 \%$ fetal bovine serum. Jurkat Tet-On cells, human acute T-cell leukemia cell line, were obtained from Clontech Laboratory (Mountain View, CA) and maintained in RPMI 1640 medium with $10 \%$ Tet System Approved FBS (Clontech Laboratory) with $200 \mu \mathrm{g} / \mathrm{ml} \mathrm{G418.} \mathrm{All} \mathrm{cells} \mathrm{were} \mathrm{grown} \mathrm{in} \mathrm{a} \mathrm{humidified} \mathrm{in-}$ cubator at $37^{\circ} \mathrm{C}$ and $5 \% \mathrm{CO}_{2}$. Polyclonal antibodies against TGF- $\beta$ RI, TGF- $\beta$ RII, phospho-Smad2, Smad2, phosphoSmad3, Smad3, Smad4, Smad7, phospho-p38, p38, phosphoSrc, Src, phospho-ERK1/2, ERK1/2, phospho-Akt, Akt, and $\beta$-actin were purchased from Cell Signaling Technology (Beverly, MA). Antibody against ICSBP was obtained from Santa Cruz Biotechnology (Santa Cruz, CA). TGF- $\beta 1$, IFN- $\gamma$, and CFSE were purchased from Invitrogen (Carlsbad, CA). SB431542, LY294002, SB203580, and U0126 were obtained from LCLabs (Woburn, MA). The Cell Counting Kit-8 (CCK-8) assay kit was obtained from Dojindo Laboratories (Kumamoto, Japan).

\section{Reverse Transcription-PCR (RT-PCR)}

Total RNA was extracted from HL60 cells using Trizol (Invitrogen) according to the manufacturer's instructions. cDNA was synthesized using the Maximum RT preMix Kit (iNtRON Biotechnology, Seoul Korea). Each reaction was performed in a thermal cycler for $60 \mathrm{~min}$ at $45^{\circ} \mathrm{C}$. cDNA fragments were amplified using the following primer pairs: $5^{\prime}$-ATGTGTGACCGGAATGGTGGT-3' (sense) and $5^{\prime}$-TTAGACGATCTGTTGGTT- $3^{\prime}$ (anti-sense). PCR was performed using a Unit Block Assembly for PTC DNA Engine system (Alpha) with a program consisting of 28 cycles of $95^{\circ} \mathrm{C}$ for $40 \mathrm{~s}, 58^{\circ} \mathrm{C}$ for $1 \mathrm{~min}$, and $72^{\circ} \mathrm{C}$ for $1 \mathrm{~min}$. PCR products were resolved on a $1 \%$ agarose gel.

\section{Detection of Apoptosis by Flow Cytometry}

Apoptosis was assessed using an apoptosis detection kit containing annexin V-FITC and propidium iodide (PI; BD Biosciences, San Jose, CA) according to the manufacturer's instructions. Cells were analyzed using the EPICS XL Flow Cytometer (Beckman Coulter, Fullerton, CA) using EXPO32 software. Bleeding of FITC fluorescence into the PI channel was eliminated by computational compensation.

\section{Measurement of Cell Proliferation}

Cells were plated at $2 \times 10^{5} / \mathrm{ml}$ in $100 \mu$ l of culture medium in a 96-well microtiter plate, and cell growth was measured using the CCK-8 assay. Briefly, cells from each well were mixed with $10 \mu \mathrm{l}$ of CCK- 8 solution and incubated for $4 \mathrm{~h}$. The absorbance at $450 \mathrm{~nm}$ from each well was measured with an ELISA plate reader from MTX Lab Systems (Vienna, VA). Alternatively, cell proliferation was analyzed by the CFSE dye dilution assay using Trace CFSE (C34554; Invitrogen) as described in the manufacturer's instructions. Cells were washed and suspended in $1 \mathrm{ml}$ of pre-warmed phosphatebuffered saline (PBS)/0.1\% BSA at a final concentration of $1 \times 10^{6}$ cells $/ \mathrm{ml}$ and then labeled for $10 \mathrm{~min}$ at $37^{\circ} \mathrm{C}$ with 
$10 \mu \mathrm{M}$ CFSE. To quench the staining, five volumes of ice-cold media were added to the cells for $5 \mathrm{~min}$ on ice, and then cells were washed three times with fresh media. Cells were then cultured under the appropriate conditions for 3 days. Cell proliferation was analyzed by flow cytometry.

\section{Immunoblot Analysis}

After washing with ice-cold PBS ( $10 \mathrm{mM} \mathrm{Na} \mathrm{HPO}_{4}$ (pH 7.4), $145 \mathrm{mM} \mathrm{NaCl}$, and $2.7 \mathrm{mM} \mathrm{KCl})$, cells were lysed with $2 \times$ SDS-PAGE sample buffer (20 mM Tris (pH 8.0), 2\% SDS, $2 \mathrm{mM}$ DTT, $1 \mathrm{mM} \mathrm{Na} \mathrm{VO}_{4}, 2 \mathrm{mM}$ EDTA, $20 \%$ glycerol), and boiled for $5 \mathrm{~min}$. The protein concentration of each sample was determined using the Micro-BCA protein assay reagent as described by the manufacturer (Thermo Scientific, Rockford, IL). Total cellular protein ( $30 \mu \mathrm{g} /$ lane) was separated by $10 \%$ SDS-PAGE and then transferred to PVDF membranes. The membranes were blocked overnight at $4{ }^{\circ} \mathrm{C}$ in TBST (20 mM Tris (pH 8.0), $150 \mathrm{mM} \mathrm{NaCl}$, and $0.05 \%$ Tween 20 ) containing either 5\% BSA (for immunoblotting with anti-phospho-Akt antibody) or $5 \%$ non-fat dried milk (for immunoblotting with the remaining antibodies). The membranes were then incubated with primary antibody overnight at $4^{\circ} \mathrm{C}$, washed three times with TBST, incubated with horseradish peroxidase-conjugated goat anti-rabbit IgG secondary antibody for $1 \mathrm{~h}$ at $37^{\circ} \mathrm{C}$, and then washed with TBST three times. The labeled proteins were visualized using enhanced chemiluminescence. When necessary, the membrane was incubated in a stripping buffer $(62.5 \mathrm{mM}$ Tris (pH 6.8), 2\% SDS, and $100 \mathrm{mM} \mathrm{DTT)} \mathrm{at} 70^{\circ} \mathrm{C}$ for $30 \mathrm{~min}$, washed extensively, blocked again with $5 \%$ non-fat milk, and then probed with a different antibody as described above.

\section{Establishment of ICSBP-Overexpressing HL-60 Cells}

Human ICSBP cDNA was amplified by PCR (5'-ATGTGTG ACCGGAATGGTGGT- $3^{\prime}$ (sense), $5^{\prime}$-TTAGACGATCTGTTG GTT-3' (anti-sense; cDNA clone MGC: 161525)) and cloned into the HindIII and XhoI site of the pcDNA3.1/V5-HisA vector (Invitrogen). Then HL-60 cells were electroporated at $1350 \mathrm{~V}, 35 \mathrm{~ms}$, one pulse with Mock- or ICSBP-containing construct using the Microporator (Digitalbiotechnology, Seoul, Korea) as described by the manufacturer. Overexpressing cells were selected with $500 \mu \mathrm{g} / \mathrm{ml}$ of G418 for 4 weeks.

\section{Establishment of Doxycycline-Inducible ICSBP Expression in Jurkat Cells}

For doxycycline-inducible expression of ICSBP using Jurkat Tet-On cells, ICSBP was subcloned into pTRE-Tight vector (EcoRI/NheI; Clontech). Briefly, Jurkat Tet-On cells were eletroporated with pTRE-Tight-Mock or pTRE-Tight-ICSBP construct using the microporator and selected with $5 \mu \mathrm{g} / \mathrm{ml}$ of puromycin for 3 weeks to obtain stable cell lines. ICSBP was induced with doxycycline $(1 \mu \mathrm{g} / \mathrm{ml})$ as described by the manufacturer.

\section{RNA Interference}

Small interfering RNAs (siRNAs) specific for human ICSBP or TGF- $\beta$ R I were purchased from Dharmacon (Lafayette, CO). HL-60-Mock or HL-60-ICSBP cells were transiently transfected with ICSBP- or TGF- $\beta$ RI-specific siRNAs using Lipofectamine 2000 (Invitrogen) or electroporation as described by the manufacturer. HL-60 cells transfected with pooled nonspecific siRNA duplexes (100 nM; Dharmacon) were used as a control. The cells were analyzed at $24 \mathrm{~h}$ post transfection.

\section{Immunofluorescence and Confocal Microscopy Imaging} Cells were placed with cytospin (1000 r.p.m. for $6 \mathrm{~min}$ ) on the slide glass and fixed in $4 \%$ paraformaldehyde for $20 \mathrm{~min}$ at $4^{\circ} \mathrm{C}$ followed by permeabilization using $0.2 \%$ Triton $\mathrm{X}-100$ in PBS for $5 \mathrm{~min}$ at room temperature, blocked in $10 \%$ normal goat serum in PBS for $30 \mathrm{~min}$ at room temperature. Cells then were incubated with anti-ICSBP antibody or nonspecific IgG overnight at $4^{\circ} \mathrm{C}$, and then washed in PBS. Cells were then exposed to Alexa 568 anti-goat IgG or DAPI (Invitrogen) for $30 \mathrm{~min}$ at room temperature. The cover slips were washed in PBS and mounted on glass slides. Cells were examined using Carl Zeiss fluorescence microscopy or inverted laser-scanning microscopy (Thornwood, NY).

\section{Data Analysis}

All data are mean values of at least three independent experiments each carried out in triplicates. Statistical significance was determined by Student's $t$-test, with $P<0.01$ taken to indicate significant differences between means.

\section{RESULTS}

\section{Upregulation of ICSBP and TGF- $\beta$ Receptor Expression} by IFN- $\gamma$ in HL-60 Cells

ICSBP is known to be induced by IFN- $\gamma$ in various cell types $^{24}$ and ICSBP mRNA is constitutively expressed in a lymphoid precursor cell line. ${ }^{13}$ HL-60, a human promyelocytic cell line, does not express detectable basal levels of ICSBP (Figure 1a). Therefore, we examined ICSBP induction in HL-60 cells by measuring ICSBP mRNA levels in IFN- $\gamma$ treated cells using RT-PCR. Higher concentrations of IFN- $\gamma$ $(250 \mathrm{IU} / \mathrm{ml})$ induced ICSBP expression, although at levels much lower than U937 cells, which were used as a positive control $^{24}$ (Figure 1a). Induction of ICSBP protein was also examined by immunoblotting (Figure $1 \mathrm{~b}$ ). As IFN- $\beta-1 \mathrm{~b}$ is known to induce TGF- $\beta$ R 1 and TGF- $\beta$ RII expression, ${ }^{25}$ we also examined whether IFN- $\gamma$ regulates TGF- $\beta$ receptor expression. Interestingly, IFN- $\gamma$ induced TGF- $\beta$ RI expression in HL-60 cells (Figure 1b). ICSBP mRNA expression was detected at $3 \mathrm{~h}$ exposure to IFN- $\gamma$ and higher levels of ICSBP at $24 \mathrm{~h}$, whereas TGF- $\beta$ receptor mRNA expression was noticed at $24 \mathrm{~h}$ (Figure 1c). Knockdown of ICSBP using siRNA specific for ICSBP blocked expressions of both ICSBP and TGF- $\beta$ receptor (Figure 1c). 


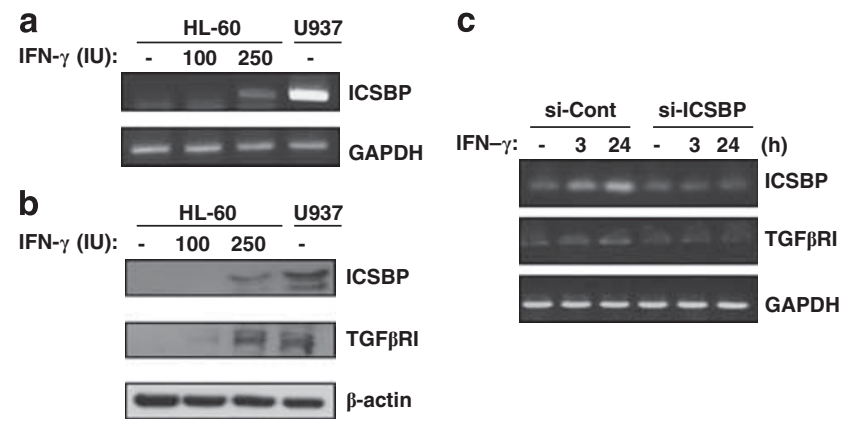

Figure 1 Effects of IFN- $\gamma$ on ICSBP expression in HL-60 cells. (a) HL-60 cells were treated with $0-250 \mathrm{IU} / \mathrm{ml}$ of IFN- $\gamma$ for $12 \mathrm{~h}$ before isolation of total RNA. To assess ICSBP mRNA levels, RT-PCR was performed using human ICSBP-specific primers. U937 cells were used as a positive control for IFN- $\gamma$ induced ICSBP expression. (b) HL-60 cells were treated with IFN- $\gamma$ as in a for $24 \mathrm{~h}$. Cell lysates were prepared and subjected to immunoblotting analysis using anti-ICSBP, anti-TGF- $\beta$ R 1 , and anti- $\beta$-actin antibodies. $\beta$-Actin levels were analyzed to control for protein loading. (c) HL-60 cells were transfected with either control siRNA (si-Cont) or siRNA specific for ICSBP (si-ICSBP) as described in the Materials and Methods, and then HL-60 cells were treated with 0 to $250 \mathrm{IU} / \mathrm{ml}$ of IFN $-\gamma$ for 3 and $24 \mathrm{~h}$ before isolation of total RNA. To assess ICSBP, TGF- $\beta$ RI, and GAPDH mRNA levels, RT-PCR was performed using human ICSBP, TGF- $\beta$ RI, GAPDH-specific primers.

Experiments were performed three times with comparable results.

\section{Effects of ICSBP Overexpression on TGF- $\beta$ Receptor Expression and Signaling}

To further investigate the role of ICSBP in TGF- $\beta$-mediated biological functions, we established a stable human ICSBPoverexpressing HL-60 cell line. Expression and nuclear localization of ICSBP were verified by immunofluorescence (Figure $2 \mathrm{a}$ ) and immunoblotting using an anti-ICSBP antibody (Figure $2 \mathrm{~b}$ ). As we observed TGF- $\beta$ R I induction by IFN- $\gamma$ in HL-60 cells (Figure 1b), we examined whether ICSBP overexpression affects TGF- $\beta$ receptor expression. Unexpectedly, ICSBP cells exhibited higher levels of TGF- $\beta$ R I and TGF- $\beta$ R II than Mock cells, indicating that ICSBP itself upregulates expression of the TGF- $\beta$ receptors (Figure $2 \mathrm{~b}$ ). We next examined whether upregulation of these receptors influences TGF- $\beta$-associated signaling events. We found that phosphorylation of Smad2 and Smad3 was higher in ICSBP cells than in Mock cells (Figure 2c). Although levels of Smad3 and Smad4 protein were higher in ICSBP cells, levels of Smad2 and Smad7 were similar (Figure 2c). More interestingly, activities of non-Smad molecules involved in TGF- $\beta$ signaling, such as Src, ERK1/2, Akt, and p38, were elevated in ICSBP cells although no difference in protein level was observed between the Mock and ICSBP cells (Figure 2d). Taken together, these data suggest that ICSBP expression leads to activation of various signaling pathways, including TGF- $\beta$ receptor signaling.

Increased Cell Proliferation Induced by ICSBP Expression As ICSBP is known as a tumor suppressor, we examined whether ICSBP expression could affect cell growth. To accomplish this, we first performed the CCK-8 assay and cell counting and we found that ICSBP cells grew faster than
Mock cells (Figure 3a and b). Alternatively, Mock and ICSBP cells were labeled with CFSE, a green fluorescence dye that labels cellular proteins and gets equally partitioned into daughter cells on cell division. After labeling, cell were grown for 3 days and analyzed by flow cytometry analysis to evaluate the dilution of CFSE fluorescence intensity, which is an indication of cell division. Similar to the results from the CCK-8 assay and cell counting, ICSBP cells contained less CFSE fluorescence than Mock cells, which means that ICSBP cells proliferate faster than Mock cells (Figure 3c). These data suggest that ICSBP overexpression results in increased cell proliferation in HL-60 cells.

As endogenous ICSBP levels are high in U937 cells (Figure 1), we knocked down ICSBP using siRNA specific for ICSBP (si-ICSBP) to investigate ICSBP effect on cell growth in U937 cells. ICSBP levels were decreased by si-ICSBP RNA transfection (Figure 3d) and, interestingly, cell growth was also decreased with knockdown of ICSBP (Figure 3e). These data indicate that endogenous ICSBP expression in the U937 cells might function for cell growth rather than cell death. To verify a role of ICSBP for cell growth in another hematopoietic cell, we transfected Jurkat cells with ICSBP cDNA under control of a doxycycline-responsive promoter. Although Jurkat cells express low levels of endogenous ICSBP, there was an increased ICSBP expression with doxycycline (Figure 4a). Concomitantly, TGF- $\beta$ R I and pSmad 2 expression was enhanced and cell growth was increased on ICSBP induction with doxycycline in Jurkat cells (Figure 4b). All these results suggest that overexpression of ICSBP is linked with cell growth.

To further explore the effect of ICSBP expression on HL-60 cell growth, we assessed cell proliferation following siRNAmediated knockdown of ICSBP. ICSBP cells transfected with si-ICSBP exhibited lower ICSBP protein levels (Figure 5a) and cell proliferation (Figure 5c) compared with cells transfected with the scrambled control siRNA. Interestingly, siRNA-mediated ICSBP knockdown also led to a decrease in TGF- $\beta$ RI protein levels (Figure $5 \mathrm{a}$ ). Therefore, we examined whether TGF- $\beta$ R I expression is important for ICSBP-induced cell proliferation. siRNA knockdown of TGF- $\beta$ R I (siTGF- $\beta$ R I) did not affect ICSBP protein levels (Figure $5 \mathrm{~b}$ ). However, a reduction in cell proliferation was observed, although to a lesser extent than that mediated by si-ICSBP (Figure 5c). These results indicate that ICSBP regulates TGF$\beta \mathrm{RI}$ expression, as knockdown of this transcription factor led to reduced TGF- $\beta$ RI levels, whereas receptor knockdown did not affect ICSBP. We further reasoned that ICSBP reexpression should rescue si-ICSBP-induced cell growth inhibition. As we expected, when cells were transfected with ICSBP after si-ICSBP expression, cell growth was recovered (Supplementary Figure 1A) and expressions of both ICSBP and TGF- $\beta$ R I were restored (Supplementary Figure 1B). Collectively, these data indicate that ICSBP expression increases cell proliferation in HL-60 cells and that this event involves TGF- $\beta$ RI upregulation. 
a

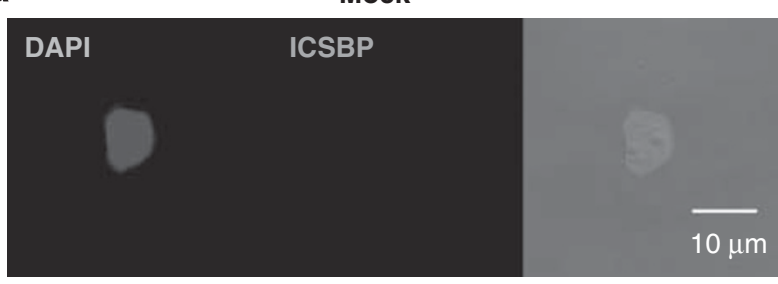

ICSBP

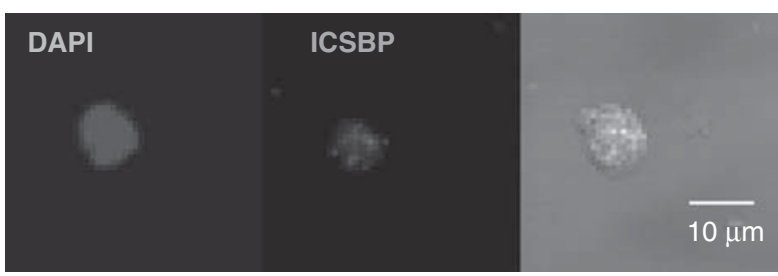

b

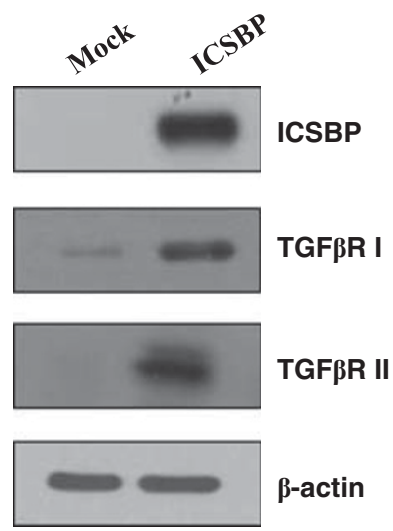

c
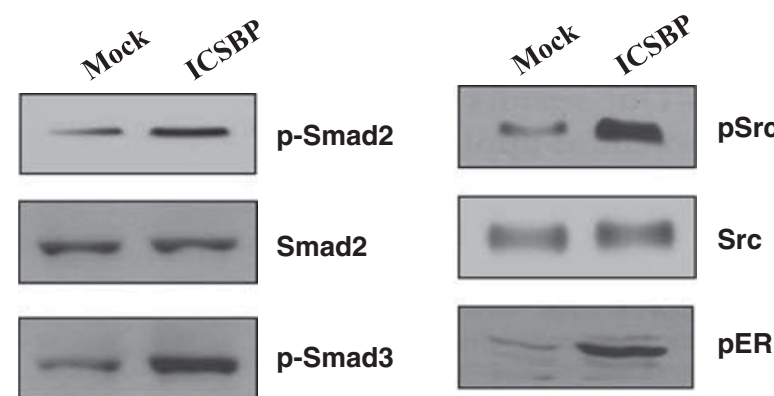

p-Smad3

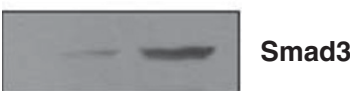

Smad4

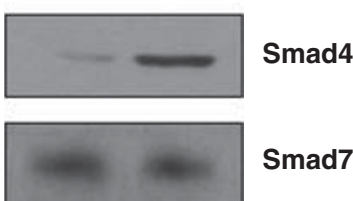

$\beta$-actin
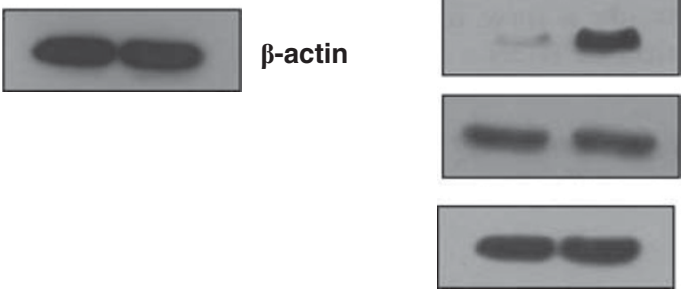

$\beta$-actin

Figure 2 Establishment of an ICSBP-overexpressing HL-60 cell line and effects of ICSBP-overexpression on various signaling pathways. (a) HL-60 cells were transfected with either an empty expression vector (Mock) or an ICSBP-expression vector (ICSBP) as described in the Materials and Methods. Stable cells were established by selection with G418. Immunofluorescence staining of ICSBP in Mock and ICSBP-expressing HL-60 cells was performed. Scale bar indicates $10 \mu \mathrm{m}$. (b) Cell lysates prepared from the Mock and ICSBP cells were analyzed by immunblotting using anti-ICSBP, anti-TGF- $\beta$ RI, anti-TGF- $\beta$ RII, and anti- $\beta$-actin antibodies. (c, d) Cell lysates from Mock and ICSBP cells were analyzed by immunblotting using antibodies against phospho-Smad2, phospho-Smad3, Smad2, Smad3, Smad4, Smad7, phospho-Src, Src, phospho-ERK1/2, ERK1/2, phospho-Akt, Akt, phospho-p38, p38, and $\beta$-actin.

Experiments were performed three times with comparable results.

To further elucidate whether increased TGF- $\beta$ receptor activity is responsible for ICSBP-mediated cell proliferation, we treated cells with a pharmacological inhibitor for TGF$\beta$ RI, SB431542, and then assessed cell growth. TGF- $\beta$ RI inhibition decreased cell growth when tested by CCK- 8 assay (Figure 5d) and this growth inhibition appeared due to spontaneous cell death (Figure 5e). SB431542 induced cell death in both Mock and ICSBP cells, but the degree of cell death by SB431542 was greater in ICBSP cells (5.3-fold of control) than in Mock cells (2.5-fold of control; Figure 5e), indicating that ICSBP cells are more dependent on TGF- $\beta$ receptor activity for cell survival than Mock cells.

\section{Involvement of the TGF- $\beta$ Receptor and p38-TAK Pathway in the Regulation of ICSBP-Induced Cell Proliferation}

To further investigate the molecular mechanisms involved in ICSBP-mediated cell growth, we examined the activities of signaling molecules associated with cell growth and survival after ICSBP or TGF- $\beta$ R I knockdown. Phosphorylation of p38 but not ERK1/2 or Akt was decreased in the presence of si-ICSBP or si-TGF- $\beta$ RI (Figure $6 \mathrm{a}$ and $\mathrm{b}$ ). To test whether p38 activity is critical for ICSBP-induced cell growth, ICSBP cells were treated with a p38 inhibitor, SB203580, for 3 days. The CCK-8 assay and cell counts revealed that cell growth was inhibited by SB203580 treatment (Figure $6 c$ and d), whereas PI3K and MEK inhibition by LY294002 and UO126, respectively, did not affect cell growth (data not shown). In addition, ICSBP-expressing cells treated with SB203580 exhibited greater apoptosis than cells incubated with LY294002 or UO126 (Figure 6e). These data indicate that ICSBPmediated TGF- $\beta$ RI induction activates $\mathrm{p} 38$, which is critical for cell growth and survival.

TGF- $\beta$-activated kinase 1 (TAK- 1 ) belongs to the MAP kinase kinase family and activates kinases such as p38 and JNK. ${ }^{26}$ Interestingly, TAK-1 is phosphorylated in ICSBP-expressing cells, indicating that this kinase is activated (Figure 7a). Consistent with this, ICSBP knockdown resulted 
a

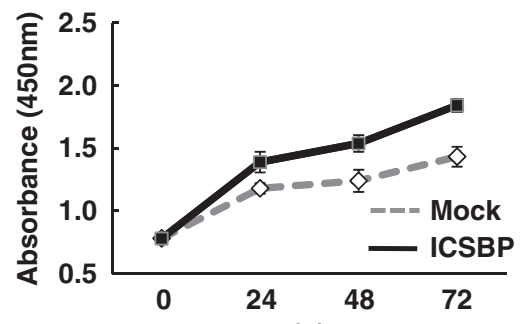

(h)

C

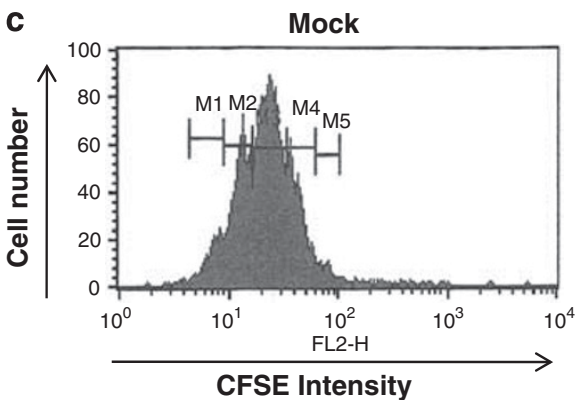

d b

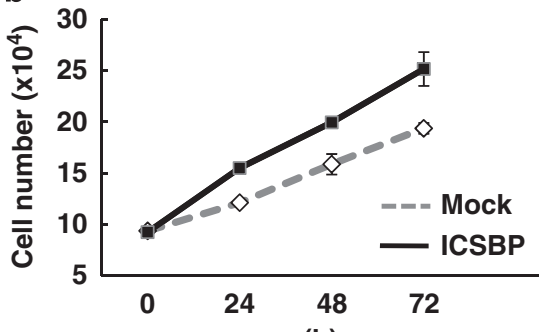

(h)

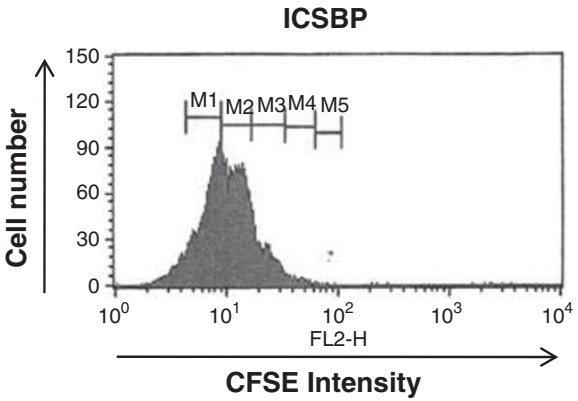

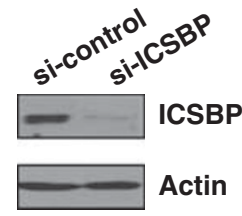

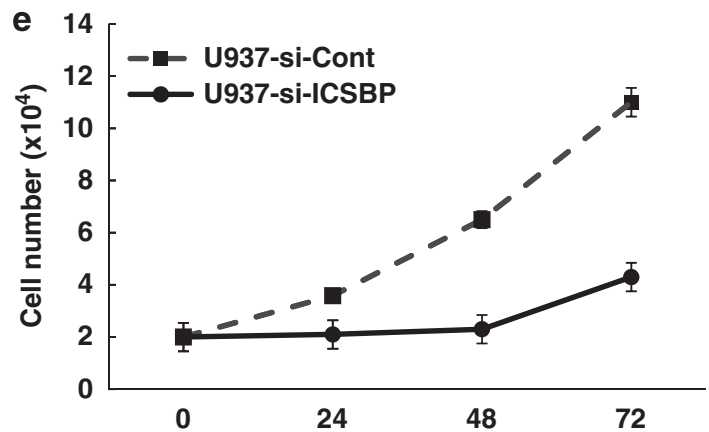

(h)

Figure 3 Effects of ICSBP expression on cell growth. (a) Equivalent numbers of cells (Mock and ICSBP) were plated and grown in media for the indicated times before cell proliferation analysis using the CCK-8 assay. (b) Cell numbers were counted after Trypan blue staining at the indicated times. The data represent the mean from three independent experiments with error bars representing the standard deviation. (c) Cells were labeled for 10 min with $10 \mu \mathrm{M}$ CFSE and staining was quenched by washing. The cells were then cultured for 3 days and analyzed for cell division pattern by flow cytometry. (d) U937 cells were transfected with control siRNA (si-control) or ICSBP-specific siRNA (si-ICSBP) by electrophoration. Cell lysates were prepared from Mock and ICSBP expressing U937 cells and analyzed by immunoblotting with ICSBP-specific antibody. (e) U937 cells transfected either with si-control or si-ICSBP were counted after Trypan blue staining at the indicated times. The data represent the mean from three independent experiments with error bars representing the standard deviation.

in TAK-1 inactivation (Figure 7b). Moreover, TGF- $\beta$ RI knockdown also decreased TAK-1 activation (Figure $7 \mathrm{~b})$. To further investigate the link between TGF- $\beta$ RI activity and TAK-1 activation, we assessed TAK-1 and p38 activity in ICSBP-expressing cells treated with a TGF- $\beta$ RI inhibitor, SB431542. As shown in Figure 7c, SB431542 attenuated the activities of TAK-1 and p38 in a time-dependent manner. As JNK is also one of the TAK-1 downstream molecules, we examined its activity and the effects of its inhibition on cell growth. Little difference in JNK phosphorylation was observed between Mock and ICSBP cells, indicating that JNK activation was not affected by ICSBP expression (Figure 7d). Treatment of Mock and ICSBP cells with a JNK inhibitor, SP600125, resulted in similar levels of cell death (Figure 7e). In contrast, ICSBP-expressing cells showed greater sensitivity to the p38 inhibitor SB203580. These data suggest that p38 is critical to the growth of ICSBP cells but not Mock cells, whereas JNK is required for the growth of both ICSBP and Mock cells. Taken together, our data illustrate that ICSBP expression induces TGF- $\beta$ RI, which potentiates TGF- $\beta$ signaling pathways such as TAK-p38 to mediate cell growth.

\section{DISCUSSION}

This study provided evidence from both overexpression and siRNA knockdown for a novel role for ICSBP in increasing HL-60 cell growth via TGF- $\beta$ receptor upregulation and subsequent activation of the TGF- $\beta$ receptor/TAK-1/p38 pathway. Although it is generally accepted that ICSBP is a tumor suppressor, we expand our current knowledge on ICSBP in relation to promotion of cell growth. 
a

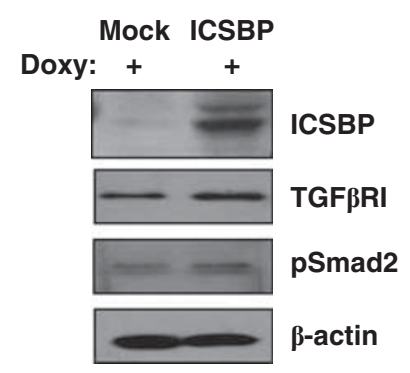

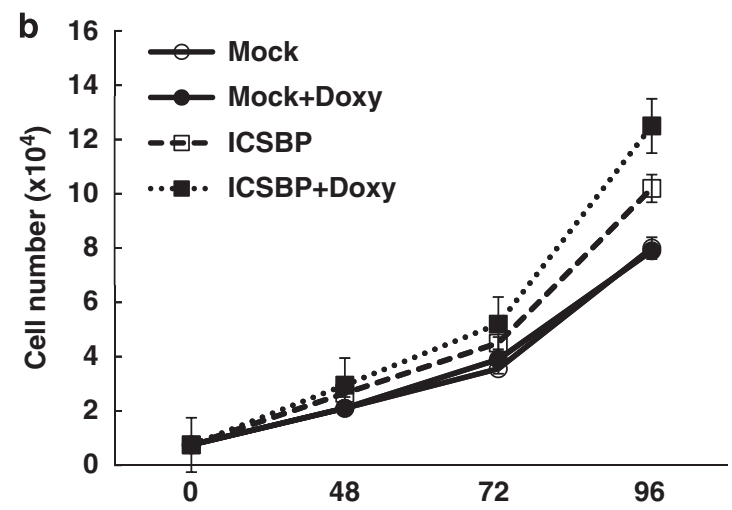

(h)

Figure 4 Effect of induced expression of ICSBP on cell growth in Jurkat Tet-On cells. Jurkat Tet-on cells were transfected with pTRE-Tight-Mock or pTRE-Tight-ICSBP constructs, respectively, and subjected to selection with puromycin to generate stable cell lines. Doxycycline $(1 \mu \mathrm{g} / \mathrm{ml}) \mathrm{was}$ added to induce protein expression and cells were harvested and assessed for proteins using anti-ICSBP, anti-TGF- $\beta$ RI, anti-phospho Smad2, and $\beta$-actin antibodies (a) or cell growth by counting at the indicated times (b).

a

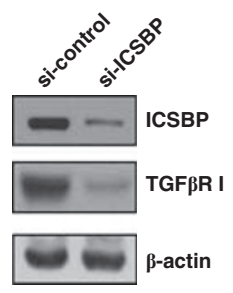

b

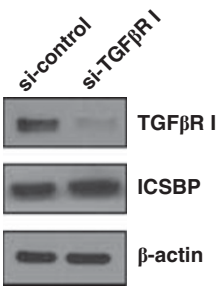

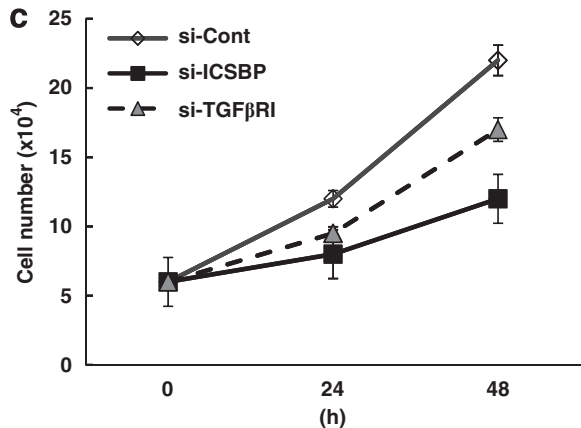

(h) d

e

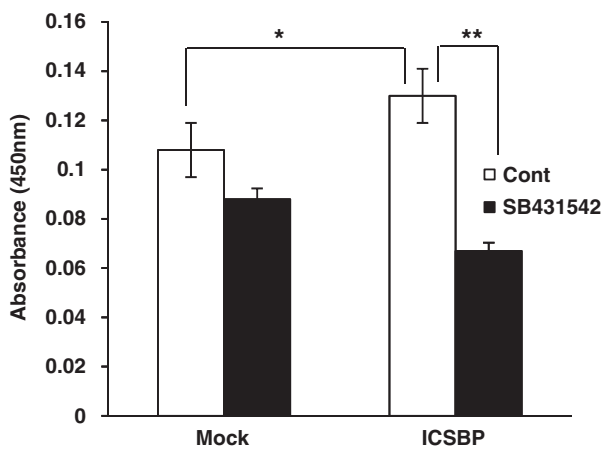

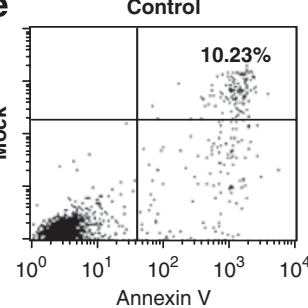

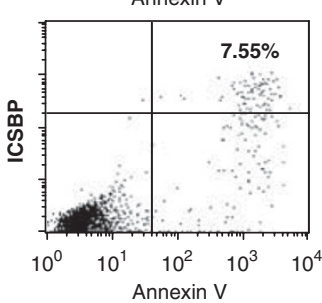

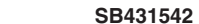
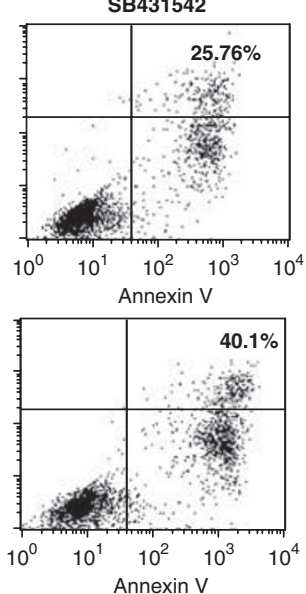

Figure 5 Effect of ICSBP expression on TGF- $\beta$ RI expression and cell growth. (a, b) ICSBP cells were transfected with control siRNA (si-control), ICSBP-specific siRNA (a), or TGF- $\beta$ R I-specific siRNA (b) by electroporation and then cultured for $48 \mathrm{~h}$. Cell lysates were prepared for immunoblotting analysis using antiICSBP, anti-TGF- $\beta$ RI, and anti- $\beta$-actin antibodies. (c) ICSBP cells were transfected with siRNAs as described above, and cell growth was measured at 24 and $48 \mathrm{~h}$ post transfection by cell counting. Experiments were performed in triplicate and error bars represent the standard deviation. (d) Cells were treated with $50 \mu \mathrm{M}$ of SB431542, a specific inhibitor of TGF- $\beta$ RI for $72 \mathrm{~h}$. Cell viability was measured using the CCK-8 assay. Experiments were performed in triplicate and error bars represent the standard deviation. ${ }^{\star}$ Statistically significant increase in absorbance between DMSO treated Mock and ICSBP cells $(P<0.01)$. ${ }^{*}$ Statistically significant decrease in absorbance between DMSO and $30 \mu \mathrm{M}$ SB431542 treated ICSBP cells $(P<0.01)$. (e) Cells were treated as described above, stained with annexin V/PI, and then analyzed by flow cytometry. The percentages of annexin-V-positive cells are indicated. Similar results were observed in two independent experiments.

ICSBP drives myeloid progenitor cell differentiation toward macrophages and inhibits granulocyte differentiation. ICSBP also strongly inhibits cell growth and positively reg- ulates apoptosis in myeloid cells (reviewed in Tamura $\mathrm{et} \mathrm{al}^{14}$ ). Studies report that ICSBP expression is absent in myeloid leukemias and some solid tumors, including nasopharyngeal 

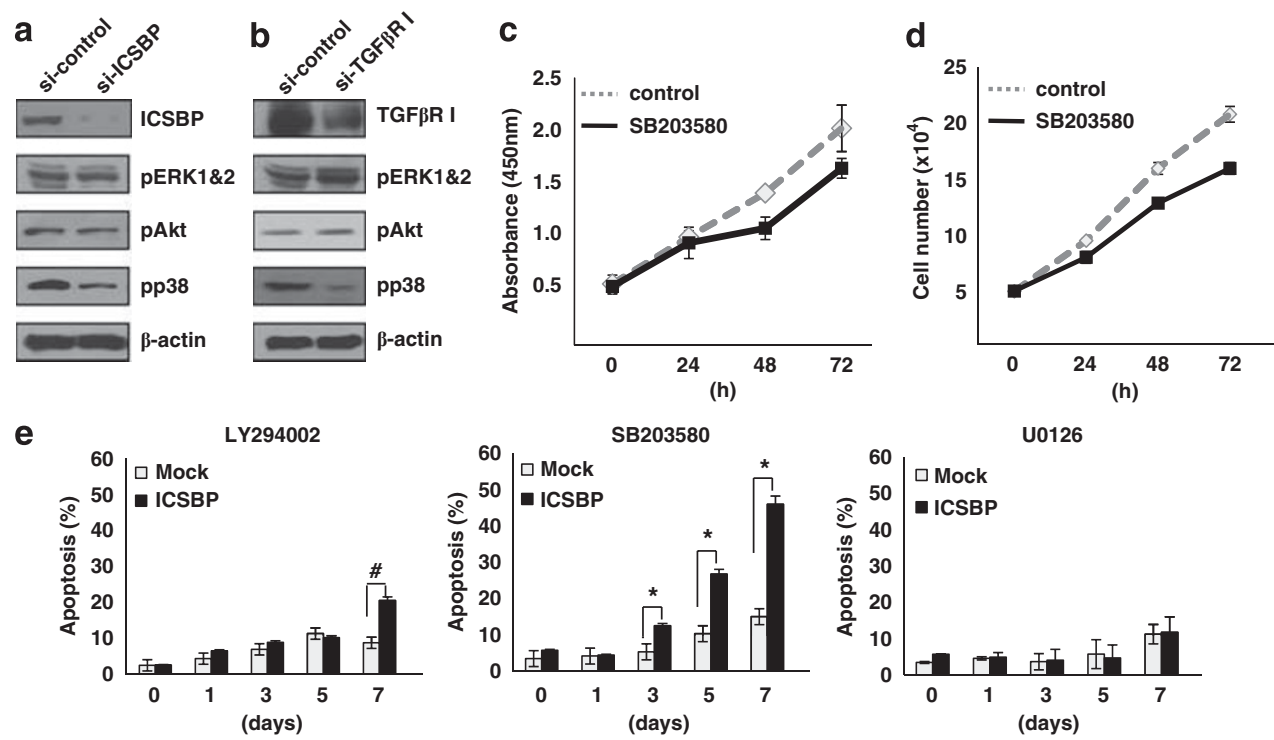

Figure 6 Effect of ICSBP-mediated p38 MAPK activation on cell growth. (a, b) ICSBP cells were transfected with siRNAs for $24 \mathrm{~h}$ as described in Figure $5 \mathrm{a}$ and $\mathrm{b}$. Cell lysates were then prepared for immunoblotting analysis using the antibodies as indicated. (c, d) ICSBP cells were treated with $50 \mu \mathrm{M} \mathrm{SB} 203580$ (p38 inhibitor) and cell growth was measured by the CCK-8 assay (c) or cell count (d). (e) Mock and ICSBP cells were treated with $10 \mu \mathrm{M} \mathrm{LY} 294002$ (PI3K inhibitor), $10 \mu \mathrm{M}$ SB203580 (p38 inhibitor), or $10 \mu \mathrm{M}$ U0126 (MEK inhibitor) for the indicated time periods, and apoptosis were measured by flow cytometric analysis of annexin-V/PI-stained cells. The average percentages of annexin V-positive cells from three independent experiments are presented with their standard deviation. Similar results were obtained from two independent experiments. ${ }^{\#} P<0.01$ versus LY294002treated Mock cells; ${ }^{*} P<0.01$ versus SB203580-treated Mock cells.

a

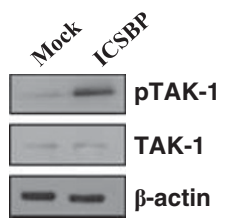

d

b

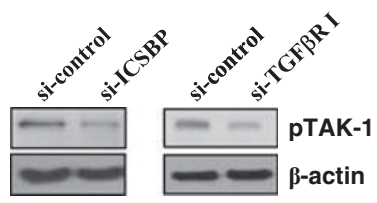

C $\begin{array}{lllll}15 & 30 & 60 & 360 & (\mathrm{~min})\end{array}$

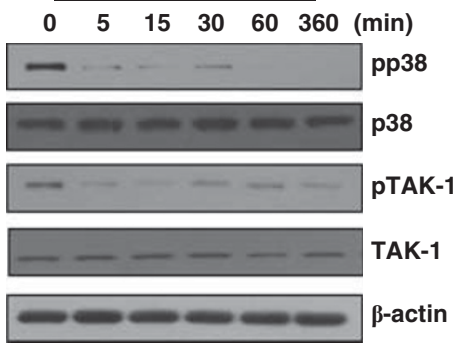

Figure 7 Effect of ICSBP expression on TGF- $\beta$ RI-TAK-1 activation. (a) Cellular proteins from Mock or ICSBP cells were subjected to immunoblotting analysis using anti-phospho-TAK1, anti-TAK1, anti- $\beta$-actin antibodies. (b) ICSBP cells were transfected with siRNAs as described in Figure 5 and cell lysates were analyzed by immunoblotting using antibodies against phospho-TAK- 1 and $\beta$-actin. (c) ICSBP cells were treated with SB431542 (TGF- $\beta$ RI inhibitor) for the indicated times and cell lysates were analyzed using anti-phospho-p38, anti-p38, anti-phospho-TAK-1, anti-TAK1, and $\beta$-actin antibodies. (d) Cellular proteins from Mock or ICSBP cells were subjected to immunoblotting analysis using anti-phospho-JNK antibodies. (e) Mock and ICSBP cells were treated with a p38 inhibitor, SB203580 (10 and $30 \mu \mathrm{M})$, or a JNK inhibitor, SP600125 (10 and $30 \mu \mathrm{M})$, for the indicated times and cell viability was measured by Trypan blue staining. The average percentages of Trypan blue-negative cells from three independent experiments are presented along with their standard deviations. Similar results were observed in two independent experiments. ${ }^{*}$ and ${ }^{*} P<0.01$ versus 10 or $30 \mu \mathrm{M}$ SB203585-treated Mock cells, respectively; ${ }^{\#}$ and ${ }^{\# \#} P<0.05$ versus 10 or $30 \mu \mathrm{M}$ SP-treated Mock cells, respectively. 
carcinomas, ${ }^{14,19}$ indicating that ICSBP functions as a tumor suppressor. Moreover, these tumors show transcriptional silencing and promoter methylation of ICSBP. ${ }^{14,19}$ In fact, the HL-60 promyelotic leukemic cell line exhibits undetectable basal levels of ICSBP. However, IFN- $\gamma$ can induce ICSBP expression, indicating that the ICSBP promoter is transcriptionally silenced but not epigenetically modified (Figure 1).

IFNs induce apoptosis in various tumor cell types, including acute promyelotic leukemia. ${ }^{27}$ Although ICSBP was induced by IFN- $\gamma$ (Figure 1), treatment with this cytokine induced minimal cell death (data not shown), suggesting that ICSBP expression is not linked to apoptosis induction in IFN- $\gamma$-treated HL-60 cells. Zhou et $l^{28}$ reported that $1000 \mathrm{U} /$ $\mathrm{ml}$ of IFN- $\gamma$ can induce apoptosis in HL-60 cells. However, $250 \mathrm{U} / \mathrm{ml}$ of IFN- $\gamma$ did not affect cell viability in our study. Unexpectedly, the level of TGF- $\beta$ RI was increased in IFN- $\gamma$ treated HL-60 cells (Figure 1). Furthermore, overexpression of ICSBP in the HL-60 resulted in enhanced expression of TGF- $\beta$ RI and TGF- $\beta$ RII (Figure 2 ), indicating that ICSBP can regulate the expression of TGF- $\beta$ receptors positively, at least in this cell line. The mechanism by which ICSBP upregulates TGF- $\beta$ receptors is currently under our investigation.

It is very intriguing that TGF- $\beta$ receptor activity is important for ICSBP-induced cell growth. Our data demonstrate that knockdown of TGF- $\beta$ RI by siRNA or pharmacological inhibition attenuated ICSBP cell growth (Figure 5), whereas increased levels of TGF- $\beta$ RI resulted in augmented TGF- $\beta$ receptor signaling, leading to cell growth. Therefore, the results are all consistent with a receptordependent mechanism.

Although TGF- $\beta$ signaling exhibits tumor suppressor activity during the early stages of tumorigenesis, this cytokine also exhibits tumor promoting activity during the later stages that favor tumor invasion and metastasis. ${ }^{4}$ These TGF- $\beta$-induced biological functions are mediated by Smad and nonSmad pathways. ${ }^{4}$ In our study, ICSBP expression enhanced Smad2 and Smad3 phosphorylation as well as upregulation of Smad3 and Smad4. Smad7, which inhibits TGF- $\beta$ signaling, remained unchanged. It is possible that ICSBP expression results in increased TGF- $\beta$ production leading to activation of downstream signaling pathways. To explore this possibility, we measured secretion of the active and latent forms of TGF- $\beta 1$ and found no significant difference between Mock and ICSBP cells (Supplementary Figure 2). In addition, incubation with a TGF- $\beta$-neutralizing antibody and TGF- $\beta$ both did not block growth of ICSBP cells (Supplementary Figures 3 and 4). Therefore, it is likely that TGF- $\beta$ receptors are constitutively activated in ICSBP cells and that increased levels of TGF- $\beta$ receptors could be sufficient to activate them without ligand binding.

ICSBP expression activated Src, ERK1\&2, Akt, and p38, and p38 activation was critical for ICSBP-induced cell growth. To further test whether ERK1 and 2, and Akt are also important for cell growth and survival, cells were treated with inhibitors to both molecules. However, little change in cell death was observed in cells treated with the inhibitors (Supplementary Figure 5). JNK and p38 are well-characterized MAPK activated by TGF- $\beta$ receptor signaling and TAK- 1 is known to activate JNK and $\mathrm{p} 38 .{ }^{26}$ In this study, we demonstrate that TAK-1 was also activated by ICSBP expression, and that this activation was diminished by siRNA knockdown of ICSBP or TGF- $\beta$ RI (Figure 7), indicating that TGF- $\beta$ RI expression is involved in TAK-1 activation. TRAF6 has been found to be critical for TGF- $\beta$-induced activation of the TAK-JNK/p38 pathway, which mediates apoptosis in response to this cytokine. ${ }^{26}$ However, in our study, activation of the TGF- $\beta$ receptor-TAK-p38 pathway by ICSBP expression had a greater role in cell growth than in cell death. When we examined Bcl-xL protein, an anti-apoptotic protein, there was little difference between ICSBP and Mock cells (data not shown). Akt, an important survival molecule, is known to phosphorylate Bad and phosphorylated Bad blocks apoptosis. ${ }^{29}$ Although Akt was activated in the ICSBP cells rather than Mock cells, there was no difference in Bad phosphorylation either (Supplementary Figure 6). It is possible that ligand-independent activation of the TGF- $\beta$ receptors by their upregulation generates different signaling events, leading to cell growth rather than apoptosis. Alternatively, ICSBP may upregulate other genes that coordinate with the TGF- $\beta$ receptor-TAK-p38 pathway to increase cell growth (Figure 8).

U937 cells express relatively high levels of endogenous ICSBP (Figure 1a and b) and overexpression of ICSBP in U937 results in an increase in spontaneous apoptosis. ${ }^{30}$ In this study, reduced cell proliferation was demonstrated by ICSBP overexpression (Supplementary Figure 7) and interestingly, knockdown of ICSBP by siRNA also induced growth

ICSBP overexpression

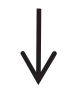

TGF $\beta R$ I, II upregulation

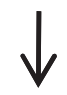

TAK-1 activation

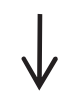

p38 MAPK activation

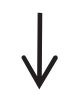

Cell proliferation and survival

Figure 8 Schematic presentation of non-Smad signaling pathways involved in ICSBP-induced $\mathrm{HL}-60$ cell proliferation. 
inhibition in U937 cells (Figure 3e). However, in HL-60 cells and Jurkat cells, whose basal ICSBP levels are very low, overexpression or induction of ICSBP resulted in cell growth promotion (Figure 4). It is possible that certain levels of ICSBP have a positive effect on cell survival, which can be disrupted by either overexpression or knockdown of ICSBP, thus leading to cell death in U937 cells. Schmidt et al ${ }^{18}$ have reported that expression of ICSBP mRNA is impaired in 27 of $34 \mathrm{CML}$ patients and 21 of 32 AML patients. Conversely, they also showed that some AML patients harbor high to very high levels of ICSBP mRNA. Therefore, it is likely that although ICSBP functions primarily as a tumor suppressor, this transcription factor may have other functions depending on the cellular context, such as cell growth modulation. Altogether, our findings suggest a novel function for ICSBP as a positive regulator of cell growth via the TGF- $\beta$ receptor-TAKp38 pathway.

Supplementary Information accompanies the paper on the Laboratory Investigation website (http://www.laboratoryinvestigation.org)

\section{ACKNOWLEDGEMENT}

This work was supported by a research grant 1010840 from the National Cancer Center, Korea.

\section{DISCLOSURE/CONFLICT OF INTEREST}

The authors declare no conflict of interest.

1. Feng $X H$, Derynck R. Specificity and versatility in tgf-beta signaling through Smads. Annu Rev Cell Dev Biol 2005;21:659-693.

2. Massague J. TGFbeta in cancer. Cell 2008;134:215-230.

3. Boulanger CA, Wagner KU, Smith GH. Parity-induced mouse mammary epithelial cells are pluripotent, self-renewing and sensitive to TGFbeta1 expression. Oncogene 2005;24:552-560.

4. Muraoka-Cook RS, Kurokawa $\mathrm{H}$, Koh $\mathrm{Y}$, et al. Conditional overexpression of active transforming growth factor beta1 in vivo accelerates metastases of transgenic mammary tumors. Cancer Res 2004;64:9002-9011.

5. Bierie B, Moses HL. TGF-beta and cancer. Cytokine Growth Factor Rev 2006;17:29-40.

6. Moustakas A, Lin $\mathrm{HY}$, Henis $\mathrm{Yl}$, et al. The transforming growth factor beta receptors types I, II, and III form hetero-oligomeric complexes in the presence of ligand. J Biol Chem 1993;268:22215-22218.

7. Derynck R, Zhang YE. Smad-dependent and Smad-independent pathways in TGF-beta family signalling. Nature 2003;425:577-584.

8. Shi Y, Massague J. Mechanisms of TGF-beta signaling from cell membrane to the nucleus. Cell 2003;113:685-700.

9. Lu T, Tian L, Han Y, et al. Dose-dependent cross-talk between the transforming growth factor-beta and interleukin-1 signaling pathways. Proc Natl Acad Sci USA 2007;104:4365-4370.

10. Hartsough MT, Mulder KM. Transforming growth factor beta activation of p44mapk in proliferating cultures of epithelial cells. J Biol Chem 1995;270:7117-7124.

11. Bakin AV, Tomlinson AK, Bhowmick NA, et al. Phosphatidylinositol 3kinase function is required for transforming growth factor beta- mediated epithelial to mesenchymal transition and cell migration. J Biol Chem 2000;275:36803-36810.

12. Wilkes MC, Mitchell H, Penheiter SG, et al. Transforming growth factorbeta activation of phosphatidylinositol 3-kinase is independent of Smad2 and Smad3 and regulates fibroblast responses via p21activated kinase-2. Cancer Res 2005;65:10431-10440.

13. Driggers $\mathrm{PH}$, Ennist $\mathrm{DL}$, Gleason $\mathrm{SL}$, et al. An interferon gammaregulated protein that binds the interferon-inducible enhancer element of major histocompatibility complex class I genes. Proc Natl Acad Sci USA 1990;87:3743-3747.

14. Tamura $T$, Yanai $H$, Savitsky $D$, et al. The IRF family transcription factors in immunity and oncogenesis. Annu Rev Immunol 2008; 26:535-584.

15. Tamura T, Nagamura-Inoue T, Shmeltzer $Z$, et al. ICSBP directs bipotential myeloid progenitor cells to differentiate into mature macrophages. Immunity 2000;13:155-165.

16. Sharf R, Meraro D, Azriel A, et al. Phosphorylation events modulate the ability of interferon consensus sequence binding protein to interact with interferon regulatory factors and to bind DNA. J Biol Chem 1997;272:9785-9792.

17. Holtschke $T$, Lohler J, Kanno $Y$, et al. Immunodeficiency and chronic myelogenous leukemia-like syndrome in mice with a targeted mutation of the ICSBP gene. Cell 1996;87:307-317.

18. Schmidt $M$, Nagel $S$, Proba J, et al. Lack of interferon consensus sequence binding protein (ICSBP) transcripts in human myeloid leukemias. Blood 1998;91:22-29.

19. Lee KY, Geng $\mathrm{H}, \mathrm{Ng} \mathrm{KM}$, et al. Epigenetic disruption of interferongamma response through silencing the tumor suppressor interferon regulatory factor 8 in nasopharyngeal, esophageal and multiple other carcinomas. Oncogene 2008;27:5267-5276.

20. Eroshkin A, Mushegian A. Conserved transactivation domain shared by interferon regulatory factors and Smad morphogens. J Mol Med 1999;77:403-405.

21. Ju XS, Ruau D, Jantti $P$, et al. Transforming growth factor beta1 upregulates interferon regulatory factor 8 during dendritic cell development. Eur J Immunol 2007;37:1174-1183.

22. Miyazaki M, Sakaguchi M, Akiyama I, et al. Involvement of interferon regulatory factor 1 and S100C/A11 in growth inhibition by transforming growth factor beta 1 in human hepatocellular carcinoma cells. Cancer Res 2004;64:4155-4161.

23. Qing J, Liu C, Choy L, et al. Transforming growth factor beta/Smad3 signaling regulates IRF-7 function and transcriptional activation of the beta interferon promoter. Mol Cell Biol 2004;24:1411-1425.

24. Weisz A, Marx P, Sharf $R$, et al. Human interferon consensus sequence binding protein is a negative regulator of enhancer elements common to interferon-inducible genes. J Biol Chem 1992:267:25589-25596.

25. Ossege LM, Sindern E, Patzold T, et al. Immunomodulatory effects of interferon-beta-1b in vivo: induction of the expression of transforming growth factor-beta1 and its receptor type II. J Neuroimmunol 1998;91:73-81.

26. Zhang YE. Non-Smad pathways in TGF-beta signaling. Cell Res 2009;19:128-139.

27. Maher SG, Romero-Weaver AL, Scarzello AJ, et al. Interferon: cellular executioner or white knight? Curr Med Chem 2007;14:1279-1289.

28. Zhou Y, Weyman CM, Liu H, et al. IFN-gamma induces apoptosis in HL60 cells through decreased $\mathrm{Bcl}-2$ and increased Bak expression. J Interferon Cytokine Res 2008;28:65-72.

29. Franke TF. PI3K/Akt: getting it right matters. Oncogene 2008;27: 6473-6488.

30. Gabriele L, Phung J, Fukumoto J, et al. Regulation of apoptosis in myeloid cells by interferon consensus sequence-binding protein. J Exp Med 1999;190:411-421. 